\title{
Development and Validation of Analytical Method for Quantitative Estimation of Multiple Metal Impurities in Dobutamine Hydrochloride using ICPMS Spectroscopy
}

\author{
Sayyad Kousr Ali, Tanmoy Mondal* \\ Department of Chemistry, Koneru Lakshmaiah Education Foundation (Deemed to be University), Hyderabad off Campus, \\ Hyderabad, Telangana, INDIA.
}

\begin{abstract}
Objectives: Primary objective of the present study is to develop and validate an accurate and linear analytical method for precise estimation of Vanadium, Cobalt, Nickel, Arsenic, Cadmium, Mercury, Thallium and Lead elemental impurities present in the Dobutamine Hydrochloride active pharmaceutical ingredient using inductively coupled plasma mass spectrometry. Materials and Methods: Argon gas is used as carrier gas and helium gas as collision gas, $5 \%$ nitric acid is used as diluent, plasma gas flow rate is $15 \mathrm{l} / \mathrm{m}$, spray chamber temperature is $2^{\circ} \mathrm{C}$, helium gas flow rate is $5 \mathrm{ml} / \mathrm{m}$, integration time is $0.3 \mathrm{~s}$ and tune mode is He gas. Microwave digester is used to extract the elemental impurities. The developed method was validated according to the Q3D guidelines provided by the International Conference on Harmonization. Results: The correlation coefficients for all the eight metals were found to be 1 , and their concentration variation (\%) in standard check solution was estimated to be less than 20 . The system precession was found to be less than $20 \%$ of relative standard deviation and the linearity calibration curve was linear over the concentration range of $0.25 \mathrm{~J}$ to $2.50 \mathrm{~J}$ specification level. The obtained recoveries are well within the acceptance criteria of $70 \%-150 \%$. Conclusion: The low relative standard deviation and high recoveries of the method confirm the suitability of the method for precise estimation of the above metal impurities in Dobutamine Hydrochloride active pharmaceutical ingredient.
\end{abstract}

Key words: Inductively Coupled Plasma Mass Spectrometer, Elemental Impurities, Method validation, Dobutamine Hydrochloride, International Conference on Harmonization.

\section{INTRODUCTION}

Dobutamine Hydrochloride (DBH) is used as medicine to treat cardiogenic shock and severe heart failure. ${ }^{1}$ However, the elemental metal impurities in this drug substance are irresistible due to the fact that it's synthesis often involves the use of reactive substances which may extant in the final drug substances as impurities. Therefore, controlling of such impurities is highly desirable to prevent any unwanted toxicities including several health and genetic problems. Thus the control of elemental metal impurities in such active pharmaceutical ingredient (API) has attracted great interest from both academia and pharmaceutical industries. Although in the recent past, such control is done by specifying the concentration of metal impurities in drug materials, the pharmaceutical manufacturers illustrate that they meet the compendial limits on some drugs by applying pharmacopeial heavy metal tests based on sulphide precipitation as demonstrated in the United States Pharmacopoeia (USP) general chapter <231> heavy metals. ${ }^{2}$ However, in 1995, the USP demonstrated several problems with the sulphide precipitation method which includes poor and variable recoveries, lack
Submission Date: 25-03-2021; Revision Date: 30-08-2021; Accepted Date: 08-10-2021

DOI: 10.5530/ijper.55.4.217 Correspondence: Dr. Tanmoy Mondal, Department of Chemistry, Koneru Lakshmaiah Education Foundation (Deemed to be University), Hyderabad off Campus, Hyderabad-500 075, Telangana, INDIA. Phone: +91-9763069080 Email - tanmoy@klh.edu.in

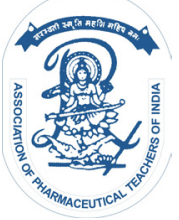

www.ijper.org 
of selectivity, loss of volatile elements, and thus the validity of the method is under question. ${ }^{3}$ Accordingly, in 1998, European medicines agency (EMA) develops a guideline on such specification limits for residues of metal impurities. ${ }^{4}$ The EMA guideline introduced massbased permitted daily exposures in drug substances rather than concentration limits on it. Several evaluations are also being done to calibrate the modern instrumental methods of analysis for elemental metal impurities in pharmaceutical ingredients. ${ }^{5-8}$ In 2008, USP established new chapter $\langle 232\rangle$ which accounts safety based limits on metal impurities in pharmaceutical products as well as suitable criteria for methods for elemental analysis. ${ }^{9}$ Later on the International Conference on Harmonization (ICH) provides the Q3D guidelines for elemental impurities as per daily exposure limit of drugs. ${ }^{10}$ A general survey of elemental impurity concentrations on commonly used pharmaceutical products and drug substances are provided recently. ${ }^{11}$ Subsequently, various researchers have used HPLC, ${ }^{12}$ UPLC, ${ }^{13}$ LC-MS/MS ${ }^{14}$ and GC-MS ${ }^{15}$ analysis methods for determining the impurities present in pharmaceutical products. In addition to the above, inductively coupled plasma mass spectrometry is recognised as one of the most sensitive multi-elemental analysis techniques which can detect trace amount of elements ranging from nanogram to picogram per milliliter $(\mathrm{ml})$. Therefore, inductively coupled plasma mass spectrometer (ICPMS) offers an exceptional sensitivity and excellent accuracy for detecting the elemental impurities at trace level. Thus, in the present work, we aim to develop an accurate, precise and linear analytical method for quantitative estimation of Vanadium (V), Cobalt (Co), Nickel (Ni), Arsenic (As), Cadmium (Cd), Mercury (Hg), Thallium $(\mathrm{Tl})$, and Lead $(\mathrm{Pb})$ elemental impurities present in the $\mathrm{DBH}$, using ICPMS spectroscopy. Microwave digester is used to extract such elemental impurities. The specification limits of the elemental impurities are considered as per the $\mathrm{Q} 3 \mathrm{D}$ guidelines provided by the $\mathrm{ICH} .{ }^{10}$ The chemical structure of DBH is shown in Figure 1.

\section{MATERIALS AND METHODS}

\section{Reagent and Materials}

Concentrated nitric acid $\left(\mathrm{HNO}_{3}\right)$ of $70 \% \mathrm{v} / \mathrm{v}$ was gifted from a reputed laboratory. The purity of this $\mathrm{HNO}_{3}$ is of trace metal grade. $5 \% \mathrm{HNO}_{3}$ is used as diluent. Deionised water was produced through a millipore water system. Dobutamine Hydrochloride drug substance and impurity standards were gifted from the reputed laboratory.

\section{Instrumentation}

The elemental impurity analysis is performed by using the Agilent ICPMS 7800 model. Calibration blank, calibration standard solutions of $0.25 \mathrm{~J}$ to $2.50 \mathrm{~J}(\mathrm{~J}=100 \%$ specification level of impurities), standard check solutions and bracketing standard check solutions aspirated to the nebulizer via peristaltic pump at $1 \mathrm{ml} / \mathrm{m}$. The details of ICPMS instrumentation conditions are as follows: the radio frequency power is 1550 watts, plasma gas flow rate is $151 / \mathrm{m}$, spray chamber temperature is $2{ }^{\circ} \mathrm{C}$, spectral peak pattern is 3 points, rate of helium gas flow is $5 \mathrm{ml} / \mathrm{m}$, integration time is $0.3 \mathrm{~s}$, tune mode is helium gas, number of metal impurities counts per second (CPS) are replicated 3 times. Nebulizer uptake speed is 0.35 revolutions per second, sample uptake time is $45 \mathrm{~s}$ and sample stabilization time is $45 \mathrm{~s}$. The microwave digester is used to extract the elemental impurities whose programme details are as follows: Microwave digester power is 1200 watts, ramp time is set as $30 \mathrm{~min}$ to reach the temperature as $160^{\circ} \mathrm{C}$ and hold the sample at $160^{\circ} \mathrm{C}$ for $20 \mathrm{~min}$ to digest it.

\section{Specification}

The specification limit of the Cadmium is $0.5 \mathrm{ppm}$, Lead is $0.5 \mathrm{ppm}$, Arsenic is $1.5 \mathrm{ppm}$, Mercury is $3 \mathrm{ppm}$, Cobalt is $5 \mathrm{ppm}$, Vanadium is $10 \mathrm{ppm}$, Nickel is $20 \mathrm{ppm}$ and Thallium is $0.8 \mathrm{ppm}$ in the sample solution.

\section{Diluent Preparation (5\% $\mathrm{HNO}_{3}$ )}

Diluent $\left(5 \% \mathrm{HNO}_{3}\right)$ was prepared by transferring $72 \mathrm{ml}$ of the above mentioned $70 \% \mathrm{v} / \mathrm{v}$ nitric acid into a $1000 \mathrm{ml}$ volumetric flask containing about $500 \mathrm{ml}$ of milli-Q-Water and made up to the volume with milli-Q Water.

\section{Preparation of Standard stock solutions}

Various standard stock solutions were prepared by transferring the substance into the diluent at various proportions. Stock A, B, D, E, F and I were prepared by transferring $0.1 \mathrm{ml}$ of $1000 \mathrm{ppm}$ of $\mathrm{Cd}, \mathrm{Pb}, \mathrm{As}, \mathrm{Hg}$, Co and $\mathrm{Tl}$ standard solution into a $10 \mathrm{ml}$ volumetric flask, respectively, and made up the volume with diluent $\left(5 \% \mathrm{HNO}_{3}\right)$. Similarly, stock $\mathrm{G}$ and $\mathrm{H}$ were prepared by transferring $1 \mathrm{ml}$ of $1000 \mathrm{ppm}$ of $\mathrm{V}$ and $\mathrm{Ni}$ standard solutions into $10 \mathrm{ml}$ volumetric flasks, respectively, and by adding $9 \mathrm{ml}$ of the above prepared diluent into the flasks. Moreover, Stock $\mathrm{C}$ was prepared by mixing $1 \mathrm{ml}$ of stock A, $1 \mathrm{ml}$ of stock $\mathrm{B}$ and $8 \mathrm{~mL}$ of the diluent. Whereas stock $\mathrm{J}$ was obtained by mixing various above prepared stock solutions in different proportions. The details were tabulated in Table 1. Additionally, Yttrium and Bismuth were added as internal standards to get 


\section{Table 1: Various components of the stock solution and the final concentrations of metals in the standard stock} solutions.

\begin{tabular}{|c|c|c|c|c|c|}
\hline $\begin{array}{l}\text { Concentration of metal } \\
(\mathrm{ppm})\end{array}$ & $\begin{array}{l}\text { Volume of } \\
\text { Stock (ml) }\end{array}$ & $\begin{array}{l}\text { Volume of } \\
\text { Diluent }(\mathrm{ml})\end{array}$ & $\begin{array}{l}\text { Final Volume } \\
(\mathrm{ml})\end{array}$ & $\begin{array}{c}\text { Final } \\
\text { Concentration } \\
(p p m)\end{array}$ & Stock Name \\
\hline$C d=1000$ & 0.1 & 9.9 & 10 & 10 & Stock-A \\
\hline $\mathrm{Pb}=1000$ & 0.1 & 9.9 & 10 & 10 & Stock-B \\
\hline Stock-A + Stock-B & 1.0 (each) & 8.0 & 10 & 1 & Stock-C \\
\hline As $=1000$ & 0.1 & 9.9 & 10 & 10 & Stock-D \\
\hline $\mathrm{Hg}=1000$ & 0.1 & 9.9 & 10 & 10 & Stock-E \\
\hline $\mathrm{Co}=1000$ & 0.1 & 9.9 & 10 & 10 & Stock-F \\
\hline$V=1000$ & 1.0 & 9.0 & 10 & 100 & Stock-G \\
\hline $\mathrm{Ni}=1000$ & 1.0 & 9.0 & 10 & 100 & Stock-H \\
\hline $\mathrm{TI}=1000$ & 0.1 & 9.9 & 10 & 10 & Stock-I \\
\hline Stock-C & 1.250 & \multirow{7}{*}{5.425} & \multirow{7}{*}{10} & $0.125(\mathrm{Cd}$ and $\mathrm{Pb})$ & \multirow{7}{*}{ Stock-J } \\
\hline Stock-D & 0.375 & & & 0.375 (As) & \\
\hline Stock-E & 0.750 & & & $0.75(\mathrm{Hg})$ & \\
\hline Stock-F & 1.250 & & & $1.25(\mathrm{Co})$ & \\
\hline Stock-G & 0.250 & & & $2.5(\mathrm{~V})$ & \\
\hline Stock-H & 0.500 & & & $5(\mathrm{Ni})$ & \\
\hline Stock-I & 0.200 & & & $0.2(\mathrm{TI})$ & \\
\hline Yttrium $=1000$ & 0.1 & \multirow{2}{*}{9.8} & \multirow{2}{*}{10} & \multirow{2}{*}{10} & \multirow{2}{*}{ Stock-K } \\
\hline Bismuth $=1000$ & 0.1 & & & & \\
\hline Stock-K & 1.0 & 9.0 & 10 & 1 & $\begin{array}{l}\text { Stock-L } \\
\text { (Internal } \\
\text { Standard) }\end{array}$ \\
\hline Aurum $=1000$ & 0.1 & 9.9 & 10 & 10 & Stock-M \\
\hline Stock-M & 1.0 & 9.0 & 10 & 1 & Stock-N \\
\hline
\end{tabular}

good recoveries of the elemental impurities. Furthermore, an Aurum standard was added to stabilize the mercury.

\section{Preparation of Calibration blank solution}

Calibration blank solution was prepared by transferring $0.1 \mathrm{ml}$ of Stock-L and $0.1 \mathrm{ml}$ of Stock-N into $10 \mathrm{ml}$ volumetric flask and diluted to volume with diluent $\left(5 \% \mathrm{HNO}_{3}\right)$.

\section{Preparation of calibration standard solutions}

Six calibration standard solutions were prepared to comply with the system (ICPMS) suitability. These were prepared with different specifications by mixing the above prepared standard stock solutions at various proportions. The final volumes of such solutions were made to $10 \mathrm{ml}$ with the diluents. The various proportions of stock solutions and the final concentrations of metals are tabulated in Table 2. It can be seen from the Table 2 that the standard check solution was obtained by mixing $0.4 \mathrm{ml}$ Stock J, $0.1 \mathrm{ml}$ of Stock L and $0.1 \mathrm{ml}$ of Stock $\mathrm{N}$ and made the total volume to 10 by adding $9.4 \mathrm{ml}$ of diluent.

\section{Sample Blank Preparation}

$5 \mathrm{ml}$ of $\mathrm{HNO}_{3}$ was taken into the digestion vessel and $0.25 \mathrm{ml}$ of Stock-N solution was added into it. It was then kept for $15 \mathrm{~min}$ and allowed the reaction to occur at atmospheric condition. Then the sample is digested in the microwave digester system. After completion of digestion, it was allowed to cool. Subsequently, $0.25 \mathrm{ml}$ 


\begin{tabular}{|c|c|c|c|c|c|c|c|c|c|c|c|c|}
\hline \multirow{2}{*}{$\begin{array}{c}\text { Stock } \\
\text { Concentration } \\
(p p m)\end{array}$} & \multirow{2}{*}{$\begin{array}{l}\text { Volume } \\
\text { of } \\
\text { Stock } \\
\text { (ml) }\end{array}$} & \multirow{2}{*}{$\begin{array}{c}\text { Volume } \\
\text { of } \\
\text { Diluent } \\
\text { (ml) }\end{array}$} & \multirow{2}{*}{$\begin{array}{c}\text { Final } \\
\text { Volume } \\
\text { (ml) }\end{array}$} & \multicolumn{7}{|c|}{ Final Concentration (ppb) } & \multirow[b]{2}{*}{ Label } & \multirow[b]{2}{*}{ Level } \\
\hline & & & & $\begin{array}{c}\mathrm{Cd} \text { and } \\
\mathrm{Pb}\end{array}$ & As & $\mathrm{Hg}$ & Co & $\mathbf{v}$ & $\mathrm{Ni}$ & $\mathrm{TI}$ & & \\
\hline Stock-J+L+N & $0.1+0.1+0.1$ & 9.7 & 10 & 1.25 & 3.75 & 7.5 & 12.5 & 25 & 50 & 2 & $\mathrm{CC}-1$ & $0.25 \mathrm{~J}$ \\
\hline Stock-J+L+N & $0.2+0.1+0.1$ & 9.6 & 10 & 2.5 & 7.5 & 15 & 25 & 50 & 100 & 4 & $\mathrm{CC}-2$ & $0.50 \mathrm{~J}$ \\
\hline Stock-J+L+N & $0.4+0.1+0.1$ & 9.4 & 10 & 5 & 15 & 30 & 50 & 100 & 200 & 8 & CC-3 & $1.00 \mathrm{~J}$ \\
\hline Stock-J+L+N & $0.6+0.1+0.1$ & 9.8 & 10 & 7.5 & 22.5 & 45 & 75 & 150 & 300 & 12 & $\mathrm{CC}-4$ & $1.50 \mathrm{~J}$ \\
\hline Stock-J+L+N & $0.8+0.1+0.1$ & 9.0 & 10 & 10 & 30 & 60 & 100 & 200 & 400 & 16 & CC-5 & $2.00 \mathrm{~J}$ \\
\hline Stock-J+L+N & $1.0+0.1+0.1$ & 8.8 & 10 & 12.5 & 37.5 & 75 & 125 & 250 & 500 & 20 & CC-6 & $2.50 \mathrm{~J}$ \\
\hline Stock- $J+L+N$ & $0.4+0.1+0.1$ & 9.4 & 10 & 5 & 15 & 30 & 50 & 100 & 200 & 8 & $\begin{array}{l}\text { Standard } \\
\text { check }\end{array}$ & $1.00 \mathrm{~J}$ \\
\hline
\end{tabular}

Note: $J=100 \%$ Specification level.

of Stock-L Solution (Internal standard) was added and diluted the solution up to $25 \mathrm{ml}$ with milli-Q Water. Finally, the solution was vortexes for $5 \mathrm{~min}$ to get the Sample blank.

\section{Sample Preparation}

$250 \mathrm{mg}$ of sample was transferred into the digestion vessel. Then $5 \mathrm{ml}$ of $\mathrm{HNO}_{3}$ and $0.25 \mathrm{ml}$ of Stock-N solution were added into it. It was then kept for $15 \mathrm{~min}$ to allow the reaction to occur at atmospheric conditions. Such a sample is then digested in the microwave digester system. After completion of digestion, it was allowed to cool and then $0.25 \mathrm{ml}$ of Stock-L Solution (Internal standard) was added and finally made up the solution to $25 \mathrm{ml}$ with milli-Q Water. At the end the final solution was vortexes for $5 \mathrm{~min}$ to get the sample.

\section{Spiked Sample Preparation}

$250 \mathrm{mg}$ of sample was transferred into the digestion vessel. Then $5 \mathrm{ml}$ of $\mathrm{HNO}_{3}, 0.25 \mathrm{ml}$ of Stock-N solution and $1 \mathrm{ml}$ of Stock-J solution were added into it. It was then kept for 15 min to allow the reaction to occur at atmospheric conditions. Next, the sample was digested in the microwave digester system. After completion of digestion, it was allowed to cool and then $0.25 \mathrm{ml}$ of Stock-L solution (Internal standard) was added. This mixture was finally diluted by making the volume $25 \mathrm{ml}$ with milli-Q Water. At the end the final solution was vortexes for $5 \mathrm{~min}$ to get the spiked sample.

\section{RESULTS}

\section{Method Validation}

Validation of the above method is verified in this section as per the Q2 (R1) and ICH guidelines. Such verifications were done by estimating the system suitability, specificity, limit of quantification, system precision, linearity, method precision, intermediate precision, accuracy and robustness and the results are given in Table 3. The procedure of these measurements is developed by injecting calibration blank, calibration standards, standard check solution, sample solution and spiked sample solution and bracketing standard solution into ICPMS. The amount of Vanadium, Cobalt, Nickel, Arsenic, Cadmium, Mercury, Thallium and Lead content present in sample solution is then calculated by using the below formula.

$$
\mathrm{ppm}=\frac{\text { Instrument Reading }(\mathrm{ppb})}{\text { Sample weight in grams }} \times \frac{\text { Dilution }}{1000}
$$

\section{System Suitability}

System suitability is established by measuring the system performance before the analysis. The response of system suitability was obtained by aspirating standard solutions with concentrations in the range from $0.25 \mathrm{~J}$ to 2.50 J of specification level. Subsequently, correlation coefficient and concentration of percent variation in standard check solution were calculated. As per the acceptance criteria provided by the ICH guidelines the correlation coefficient for all the eight metals should be 0.99 or above, and their concentrations in standard check solution should not vary more than $\pm 20 \%$ of actual concentration. Our results are shown in Table 3. As can be seen from Table 3 that the correlation coefficients for Vanadium, Cobalt, Nickel, Arsenic, Cadmium, Mercury, Thallium and Lead were found to be 1.0. And concentration variations of the above metal impurities in standard check solution were found to be $0.2,0.0,0.9,0.9,1.8,0.1,0.1$ and 0.8 percent in the same order. 


\begin{tabular}{|c|c|c|c|c|c|c|c|c|}
\hline Parameters & \multicolumn{8}{|c|}{ Results } \\
\hline \multirow{4}{*}{ System suitability } & \multicolumn{8}{|c|}{ Correlation Coefficient $(r)$} \\
\hline & $V=1.0$ & $\mathrm{Co}=1.0$ & $\mathrm{Ni}=1.0$ & As $=1.0$ & $C d=1.0$ & $\mathrm{Hg}=1.0$ & $\mathrm{Tl}=1.0$ & $\mathrm{~Pb}=1.0$ \\
\hline & \multicolumn{8}{|c|}{ Concentration of $\%$ Variation in standard check solution } \\
\hline & $V=0.2$ & $\mathrm{Co}=0.0$ & $\mathrm{Ni}=0.9$ & As $=0.9$ & $C d=1.8$ & $\mathrm{Hg}=0.1$ & $\mathrm{Tl}=0.1$ & $\mathrm{~Pb}=0.8$ \\
\hline Specificity & \multicolumn{8}{|c|}{ No Calibration blank interference was observed. } \\
\hline LOQ (ppm) & $V=2.5$ & $\mathrm{Co}=1.3$ & $\mathrm{Ni}=5.0$ & As $=0.4$ & $\mathrm{Cd}=0.1$ & $\mathrm{Hg}=0.8$ & $\mathrm{Tl}=0.2$ & $\mathrm{~Pb}=0.1$ \\
\hline $\begin{array}{c}\text { System Precision } \\
(\% \text { RSD })\end{array}$ & $V=2.3$ & $\mathrm{Co}=2.5$ & $\mathrm{Ni}=2.5$ & As $=0.8$ & $\mathrm{Cd}=2.9$ & $\mathrm{Hg}=3.5$ & $\mathrm{Tl}=1.8$ & $\mathrm{~Pb}=1.9$ \\
\hline \multirow{2}{*}{ Linearity } & \multicolumn{8}{|c|}{ Correlation Coefficient $(r)$} \\
\hline & $V=1.0$ & $\mathrm{Co}=1.0$ & $\mathrm{Ni}=1.0$ & $A s=1.0$ & $\mathrm{Cd}=1.0$ & $\mathrm{Hg}=1.0$ & $\mathrm{Tl}=1.0$ & $\mathrm{~Pb}=1.0$ \\
\hline Method Precision (\% RSD) & $V=0.3$ & $\mathrm{Co}=0.3$ & $\mathrm{Ni}=0.5$ & As $=0.4$ & $C d=0.7$ & $\mathrm{Hg}=0.4$ & $\mathrm{Tl}=1.4$ & $\mathrm{~Pb}=1.1$ \\
\hline $\begin{array}{c}\text { Intermediate precision } \\
(\% \mathrm{RSD})\end{array}$ & $V=0.6$ & $\mathrm{Co}=0.3$ & $\mathrm{Ni}=0.5$ & $A s=0.4$ & $\mathrm{Cd}=0.3$ & $\mathrm{Hg}=0.3$ & $\mathrm{Tl}=1.5$ & $\mathrm{~Pb}=1.9$ \\
\hline \multirow{2}{*}{$\begin{array}{c}\text { Accuracy } \\
\text { (\% Recovery) }\end{array}$} & $\mathrm{V}$ & Co & $\mathrm{Ni}$ & AS & $\mathrm{Cd}$ & $\mathrm{Hg}$ & $\mathrm{Tl}$ & $\mathrm{Pb}$ \\
\hline & $97-109$ & $97-106$ & $98-107$ & $91-108$ & $94-106$ & $82-103$ & $93-102$ & $91-93$ \\
\hline Robustness Acid (+5\%) & $V=0.3$ & $\mathrm{Co}=0.2$ & $\mathrm{Ni}=0.4$ & $A S=0.3$ & $C d=0.6$ & $\mathrm{Hg}=0.4$ & $\mathrm{TI}=1.4$ & $\mathrm{~Pb}=1.3$ \\
\hline $\begin{array}{c}\text { Robustness Acid }(-5 \%) \\
(\% \text { RSD) }\end{array}$ & $V=0.2$ & $\mathrm{Co}=0.2$ & $\mathrm{Ni}=0.4$ & $\mathrm{AS}=0.3$ & $\mathrm{Cd}=0.8$ & $\mathrm{Hg}=0.4$ & $\mathrm{Tl}=1.5$ & $\mathrm{~Pb}=1.3$ \\
\hline $\begin{array}{c}\text { Robustness } 0.45 \mathrm{rps} \\
(\% \mathrm{RSD})\end{array}$ & $V=0.3$ & $\mathrm{Co}=0.2$ & $\mathrm{Ni}=0.4$ & $A S=0.4$ & $\mathrm{Cd}=1.3$ & $\mathrm{Hg}=0.4$ & $\mathrm{Tl}=1.3$ & $\mathrm{~Pb}=1.6$ \\
\hline $\begin{array}{c}\text { Robustness } 0.25 \text { rps } \\
(\% \text { RSD })\end{array}$ & $V=0.3$ & $\mathrm{Co}=0.2$ & $\mathrm{Ni}=0.4$ & $A S=0.5$ & $\mathrm{Cd}=1.3$ & $\mathrm{Hg}=0.5$ & $\mathrm{Tl}=1.3$ & $\mathrm{~Pb}=1.5$ \\
\hline
\end{tabular}

rps: revolution per second, RSD: Relative standard deviation, LOQ: Limit of quantification.

\section{Specificity}

In specificity, the procedure must be able to unequivocally assess each target element in the presence of components that may expect to be present, including matrix components. The calibration blank solution and calibration curve standards are injected in to the ICPMS to measure the specificity parameters. Blank interference was evaluated by measuring the percent of interference of six replicate injections of calibration blank solutions and comparing the response with respect to calibration standard solution-1 (CC-1) response. The acceptance criteria for this are as follows: the interference of calibration blank for all the eight metal impurities shouldn't be more than 20\% of response (counts per second) of the CC-1. In the present study the calibration blank average counts per second (CPS) for Vanadium, Cobalt, Nickel, Arsenic, Cadmium, Mercury, Thallium and Lead found to be less than the $20 \%$ of counts per second of the CC-1. Therefore, no calibration blank interference was observed indicating that the specificity parameters are well within the acceptance criteria provided by $\mathrm{ICH}$.

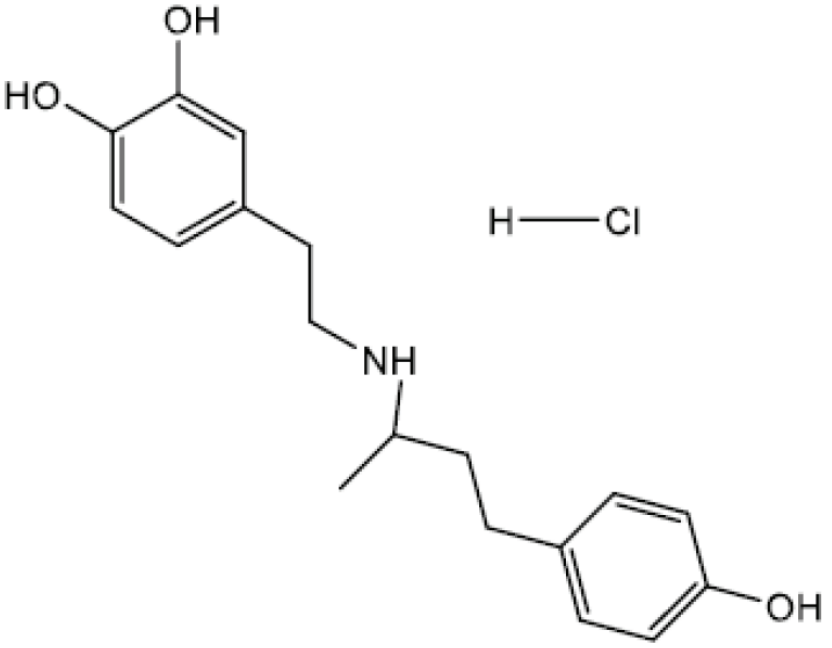

Figure 1: Chemical structure of Dobutamine hydrochloride.

\section{Limit of Quantification}

To valid the limit of quantification, first six replicates of sample blank solution are injected into ICPMS. Subsequently, limit of quantification is estimated by 
Table 4: Linearity Graphs for Vanadium, Cobalt, Nickel, Arsenic, Cadmium, Mercury, Lead and Thallium. Linearity for Vanadium

\begin{tabular}{|c|c|}
\hline Concentration (ppm) & Response (CPS) \\
\hline 2.5 & 111335.75 \\
\hline 5 & 231560.93 \\
\hline 10 & 461954.44 \\
\hline 15 & 712938.21 \\
\hline 20 & 967096.44 \\
\hline 25 & 1224417.99 \\
\hline Slope & 49421 \\
\hline Y-Intercept & -20138 \\
\hline Correlation coefficient & 1.0 \\
\hline
\end{tabular}

Linearity for Cobalt

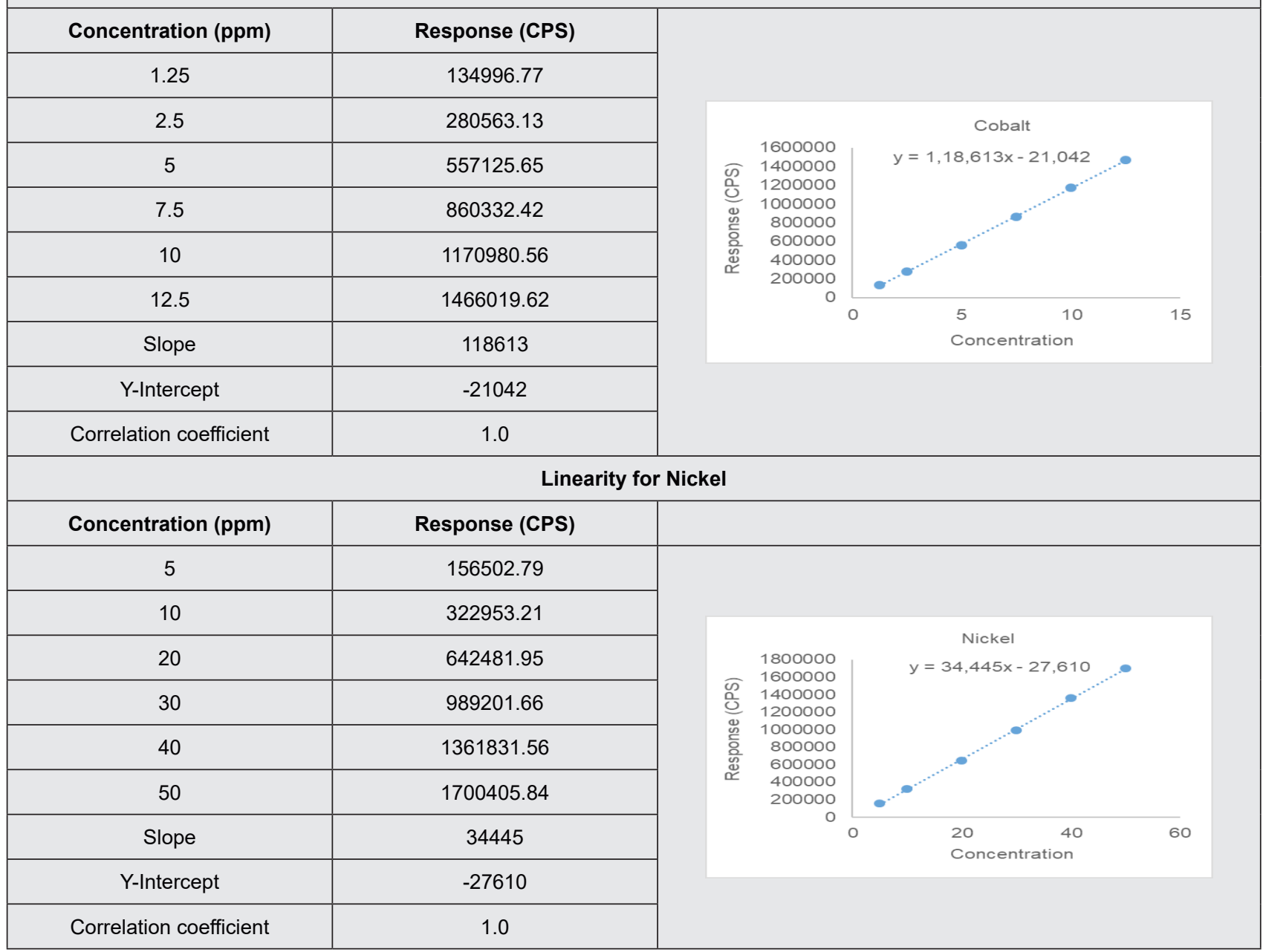




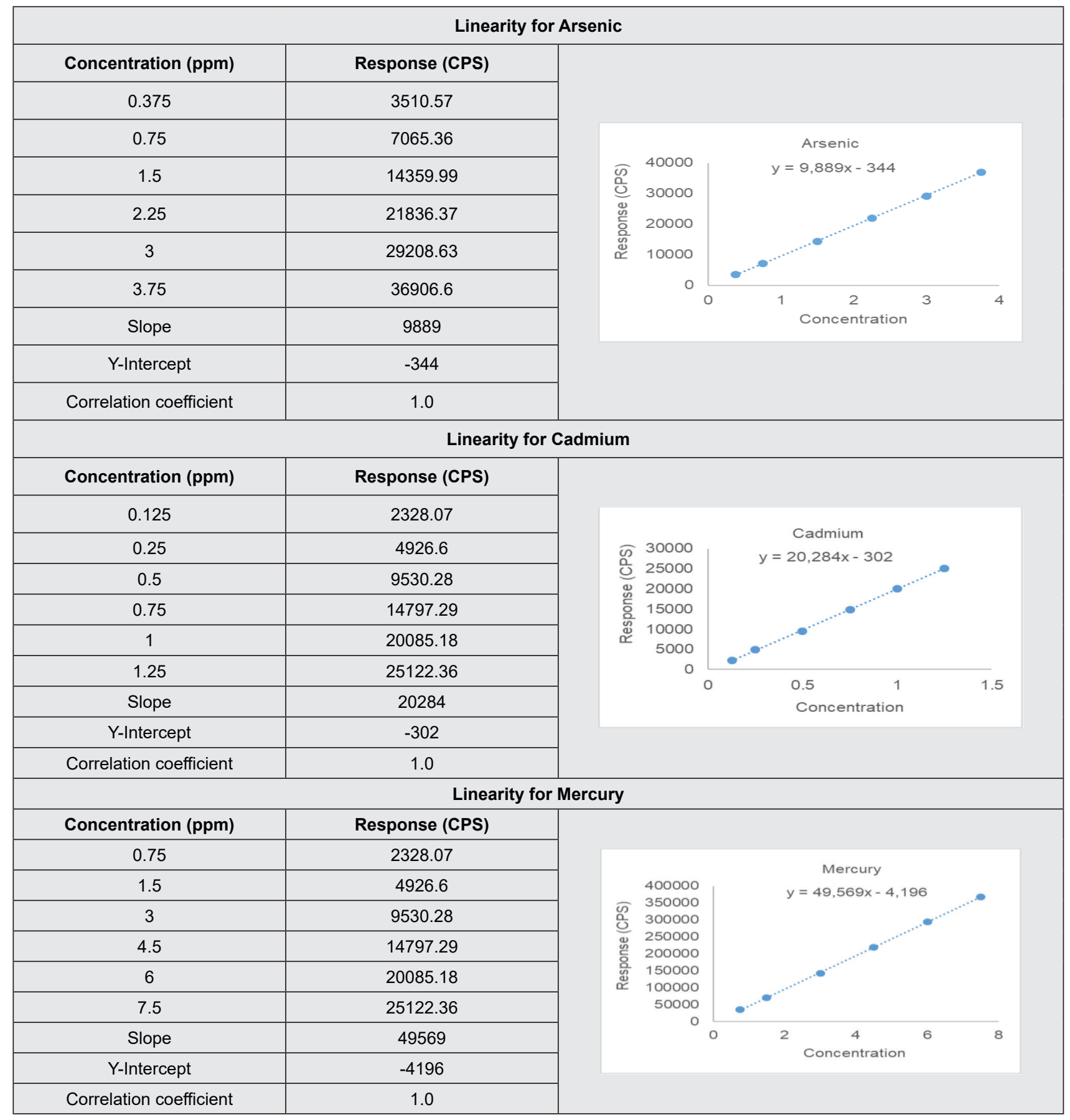




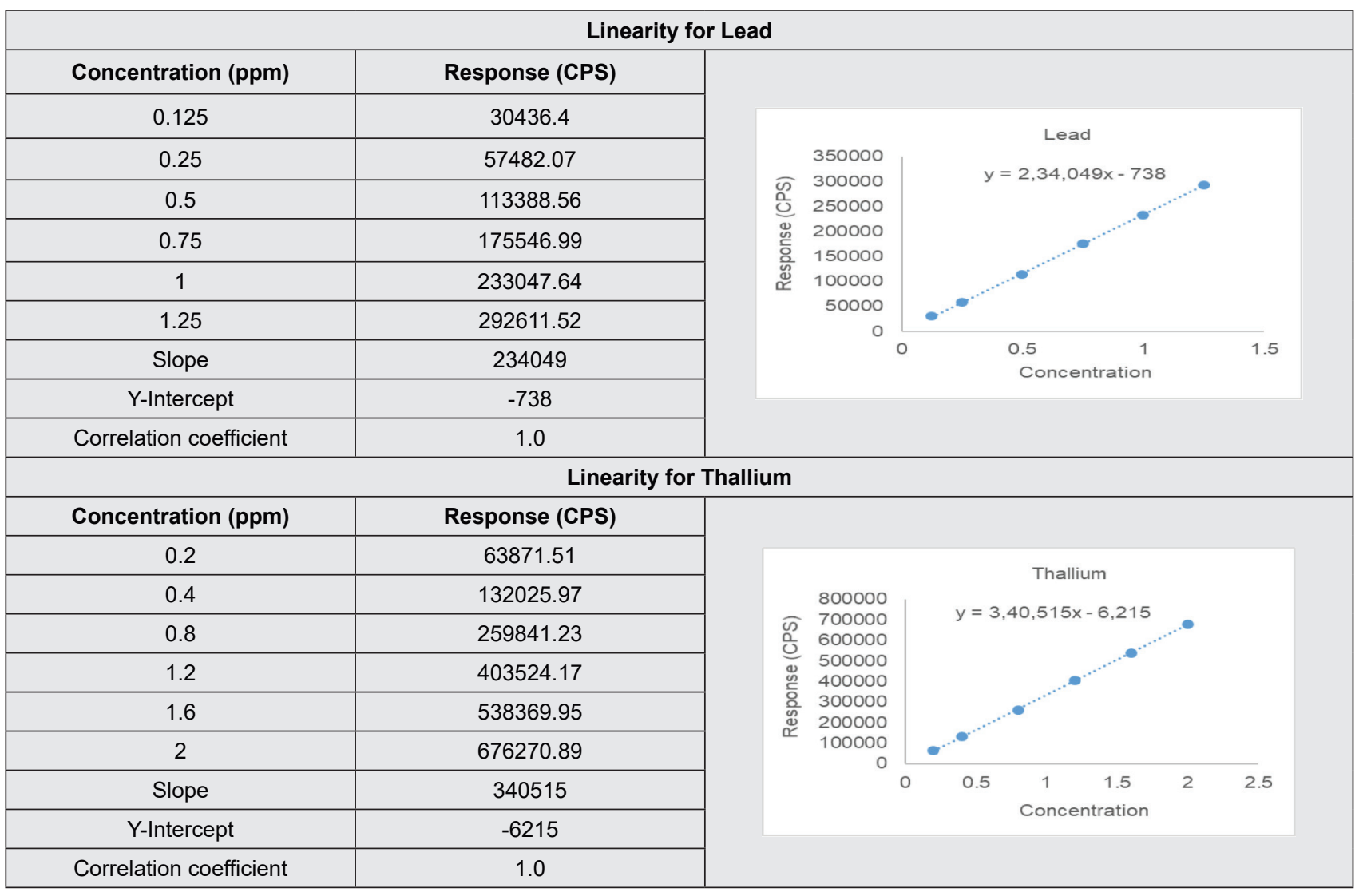

taking the ratio of impurity CPS in sample blank solution with internal standard CPS. Such a ratio for the above mentioned eight metal impurities are found to be less than the $0.25 \mathrm{~J}$ of the specification level and $0.25 \mathrm{~J} \mathrm{level} \mathrm{is} \mathrm{considered} \mathrm{as} \mathrm{the} \mathrm{limit} \mathrm{of} \mathrm{quantification}$ in the present study.

\section{System Precision}

System precision is measured by injecting six replicates of calibration standard solution-3 into ICPMS and measuring the percentage of relative standard deviation (RSD) of their CPS. We note that the acceptance criteria of the percentage of RSD for the above metal impurities given by USP <233> should be less than 20\%. In the present study, the percentage of RSD in terms of CPS of the Vanadium, Cobalt, Nickel, Arsenic, Cadmium, Mercury, Thallium and Lead are found to be 2.3, 2.5, $2.5,0.8,2.9,3.5,1.8$ and 1.9 , respectively.

\section{Linearity}

Linearity of the curve in response (CPS) vs concentration plots for calibration standard solutions were established with concentration ranging from $0.25 \mathrm{~J}$ to $2.50 \mathrm{~J}$ specification level. These results are shown in Table 4. The correlation coefficients for all the metal impurities were found to be 1.0.

\section{Method Precision}

To validate the method precision, sample blank, samples and six different $100 \%$ spiked samples were injected in to ICPMS and recorded the percentage of RSD of impurities content (ppm) for all the six 100\% spiked samples. The percentage of RSD for those six spiked samples of the Vanadium, Cobalt, Nickel, Arsenic, Cadmium, Mercury, Thallium and Lead found to be $0.3,0.3,0.5,0.4,0.7,0.4,1.4$ and 1.1 , respectively which are well within the acceptance criteria of the metal impurities provided by USP <233>. The intermediate precision is also validated by different analyst on different day. Such a results for the above metal impurities are found to be $0.6,0.3,0.5,0.4,0.3,0.3,1.5$ and 1.9 in the same order as above.

\section{Accuracy}

The accuracy is also established by injecting sample blank, sample and spike samples with 25\%, 50\%, $100 \%, 150 \%, 250 \%$ specification levels. The percentage of recovery (Minimum - Maximum) for Vanadium, Cobalt, Nickel, Arsenic, Cadmium, Mercury, Thallium and Lead are found to be 97-109\%, 97-106\%, 98-107\%, $91-108 \%, 94-106 \%, 82-103 \%, 93-102 \%$ and $91-93 \%$, respectively which are within the acceptance criteria of $70-150 \%$, as provided by ICH guidelines. 


\section{Robustness}

The robustness shows the reliability of an analysis with respect to deliberate variations in method parameters. To check the robustness of the method, $\pm 5 \%$ of $\mathrm{HNO}_{3}$ are added to the sample blank, sample and spike samples. And then the peristaltic uptake speeds in ICPMS are varied by \pm 0.1 rotation per second (RPS). The percentage of RSD for spiked samples of the Vanadium, Cobalt, Nickel, Arsenic, Cadmium, Mercury, Thallium and Lead found to be $0.3,0.2,0.4,0.3,0.6$, $0.4,1.4$ and 1.3 , respectively, when the concentration of $\mathrm{HNO}_{3}$ are varied by $+5 \%$. Similarly, the percentages of $\mathrm{RSD}$ are found to be $0.2,0.2,0.4,0.3,0.8,0.4,1.5$ and 1.3 , respectively, when the concentration of the acid is varied by $-5 \%$. The Robustness of the method is also established by varying peristaltic uptake speed by \pm 0.1 RPS. The percentages of RSD for spiked samples of the Vanadium, Cobalt, Nickel, Arsenic, Cadmium, Mercury, Thallium and Lead are found to be $0.3,0.2,0.4,0.4,1.3$, $0.4,1.3$ and 1.6, respectively, when peristaltic uptake speed is varied by +0.1 RPS. Subsequently percentages of RSD for spiked samples of the above metal impurities are found to be $0.3,0.2,0.4,0.5,1.3,0.5,1.3$ and 1.5, respectively, in the same order as above upon variation of peristaltic uptake speed by +0.1 RPS.

\section{DISCUSSION}

As can be inferred from above sections that the present method is developed by injecting calibration blank, calibration standards, standard check solution, sample blank solution, sample solution, spiked sample solution and bracketing standard solution. The validation of the method is done by performing system suitability, specificity (Blank interference), limit of quantification, system precision, method precision, intermediate precision, linearity, accuracy and robustness. It can also be seen from the method validation result tables, that all the results are well within the acceptance criteria provided by the ICH Guidelines and USP <232> and $<233>$ guidelines. The calibration blank CPS are less than $20 \%$ of the CC- 1 CPS. The correlation coefficient of all the elements was more than 0.99 . The recoveries of spiked samples were within the limit of $70 \%$ to $150 \%$. Therefore, the present method is in very good compliance with the ICH Guidelines, USP <232> and $<233>$ guidelines, and can be used routinely to estimate the above mentioned metal impurities in Dobutamine Hydrochloride drug substance at trace level.

\section{CONCLUSION}

We have developed an analytical method for simultaneous estimation of multiple elemental metal impurities in Dobutamine Hydrochloride using inductively coupled plasma mass spectrometry. Microwave digester is used to extract the elemental impurities. This method is validated linearly, precisely and accurately for Vanadium, Cobalt, Nickel, Arsenic, Cadmium, Mercury, Thallium and Lead elemental impurities in $\mathrm{DBH}$ as per the Q3D guidelines provided by ICH, USP <232> and <233>. Therefore, the above method may be used routinely for quantitative analysis of Vanadium, Cobalt, Nickel, Arsenic, Cadmium, Mercury, Thallium and Lead elemental impurities in DBH.

\section{ACKNOWLEDGEMENT}

The authors express their thanks to K.L. University for support and providing the research facility to carrying out the work.

\section{CONFLICT OF INTEREST}

The authors declare no conflict of interest.

\section{ABBREVIATIONS}

ICP-MS: Inductively Coupled Plasma Mass Spectrometer; DBH: Dobutamine Hydrochloride; HPLC: High Performance Liquid Chromatography; UV: Ultraviolet; ICH: International Conference on Harmonization; USP: United States of Pharmacopoeia; LOQ: Limit of Quantification; RSD: Relative Standard Deviation; RPS: Rotation per Second; CPS: Counts per Second; V: Vanadium; Co: Cobalt; Ni: Nickel; As: Arsenic; Cd: Cadmium; Hg: Mercury; T1: Thallium; Pb: Lead.

\section{REFERENCES}

1. [cited 29/7/2021]Available from: https://en.wikipedia.org/wiki/Dobutamine

2. United States Pharmacopeia and national formulary (USP 38-NF 33). Heavy Met;231.

3. Blake KB. Harmonization of the USP, EP and JP heavy metals testing procedures.

4. European Medicines Agency, Committee for Medicinal Products for Human Use. Guideline on the specification limits for residues of metal catalysts or metal reagents.

5. Wang T, Wu J, Jia X, Santos I, Egan RS. An atomic spectroscopic method as an alternative to both USP heavy metal and USP residue on ignition. Stimuli to the revision process. USP Pharmacopeial Forum. Vol. 29(4); 2003. p. 1328-36.

6. Geary JT. Changes to USP general chapter heavy metals. Stimuli to the revision process. USP Pharmacopeial Forum. Vol. 2004; 2004. p. 30(5). 
Schenkenberger M, Lewen N. inductively coupled plasma - optical emission spectroscopy as an alternative to the heavy metals test. Stimuli to the revision process. USP Pharmacopeial Forum. Vol. 30(6); 2004.

8. Van Hoecke K, Catry C, Vanhaecke F. Optimization of sample preparation and a quadrupole ICP-MS measurement protocol for the determination of elemental impurities in pharmaceutical substances in compliance with USP guidelines. J Anal At. Spectrum. 2012;27:1909-19.

9. The United States Pharmacopeia. Elemental impurities limits $<232>$. In process revision.

10. International Conference on Harmonization. Final concept. [accessed Aug 26, 2015]; 2009:Paper Q3D: Impurities: Guideline for elemental impurities.

11. Li G, Schoneker D, Ulman KL, Sturm JJ, Thackery LM, Kauffman JF. Elemental impurities in pharmaceutical excipients. J Pharm Sci. 2015;104(12):4197-206. doi: 10.1002/jps.24650, PMID 26398581.
12. Nekkala K, kumar S. JV, Ramachandran D. Development and validation for the simultaneous estimation of lamivudine, tenofovir disproxil and dolutegravir in drug product by RP-HPLC. J Pharm Sci Res. 2017;9:1505-10.

13. Ajay Babu M, Krishna Mohan GV, Satish J, Kalariya PD, Krishnam Raju C Mankumare SD. A Sensitive, Stability indicating UPLC method for the identification and characterization of forced degradation products for drometrizole Trisiloxane through MS ${ }^{n}$ studies. J App Pharm Sci. 2018;8(6):65-74. doi: 10.7324/JAPS.2018.8609.

14. Yelampalli SR, Jagarlapudi VSK, Mallu UR. Development and validation of genotoxic impurity in esomeprazole magnesium trihydrate active pharmaceutical ingredient by LC-MS/MS. Indian J Pharm Educ Res. 2019;53(4s):s642-9. doi: 10.5530/ijper.53.4s.160.

15. Tatipamula VB, Killari KN, Gopaiah KV, Ketha A. GC-MS Analysis of ethanol Extract of Taxithelium napalense (Schwaerg) Broth along with its alphaglucosidase Inhibitory Activity. pharmaceutical-sciences;81(3). doi: 10.36468/ pharmaceutical-sciences.547.

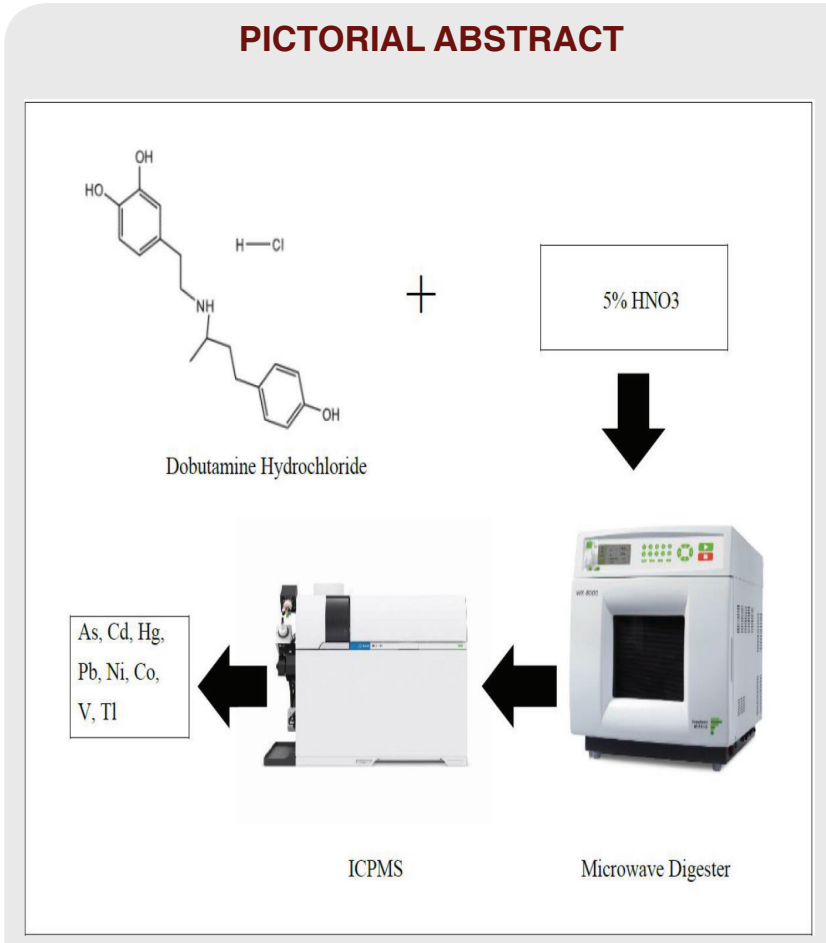

\section{SUMMARY}

An accurate and linear analytical method was developed for quantitative estimation of trace level of Vanadium, Cobalt, Nickel, Arsenic, Cadmium, Mercury, Thallium and Lead elemental impurities present in Dobutamine Hydrochloride drug by using inductively coupled plasma mass spectrometer (ICPMS). While the ICPMS identifies the trace metal impurities by their mass number up to parts per trillion levels, such a trace level cannot provide good response in HPLC or UV detection. In the present method 5\% nitric acid was used as diluent, Yttrium and Bismuth was used as internal standards. The ICPMS specifications were set up as follows: plasma gas flow rate is 15 $1 / \mathrm{m}$, spray chamber temperature is $2^{\circ} \mathrm{C}$, helium gas flow rate is $5 \mathrm{ml} / \mathrm{m}$, integration time is $0.3 \mathrm{~s}$ and tune mode is helium gas. This method was further validated by guidelines provided by Q3D(R1), ICH, USP <232> and USP <233>. Our developed method is specific, linear, precise, accurate and robust. Thus the present method can be used routinely for regular analysis in quality control and research laboratory.

\section{About Authors}

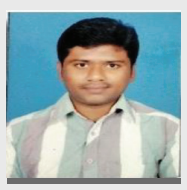

Kousr Ali Sayyad has completed M.Sc Analytical Chemistry from Andhra University. Currently pursuing $\mathrm{PhD}$ at the Department of Chemistry, Koneru Lakshmaiah Education Foundation (Deemed to be University), Hyderabad

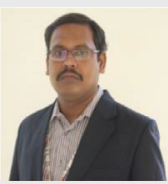
Dr. Tanmoy Mondal, is an Associate Professor, Department of Chemistry, Koneru Lakshmaiah Education Foundation (Deemed to be University), Hyderabad off Campus, Hyderabad- 500 075, India. India.

Cite this article: Ali SK, Mondal T. Development and Validation of Analytical Method for Quantitative Estimation of Multiple Metal Impurities in Dobutamine Hydrochloride using ICPMS Spectroscopy. Indian J of Pharmaceutical Education and Research. 2021;55(4):1173-82. 